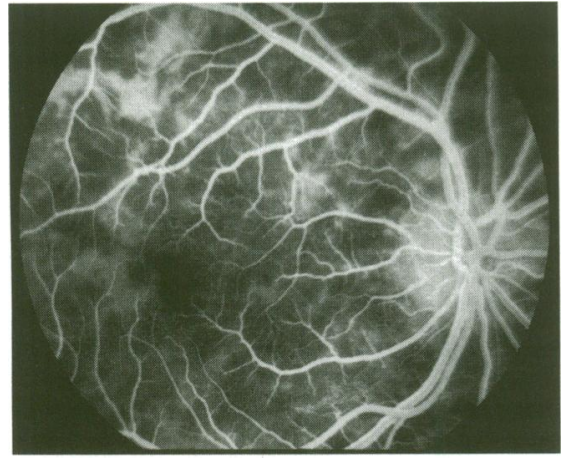

Fig $1 B$

Figure 1 (A) Right fundus showing diffusely abnormal pigment epithelium but normal retinal vessels. (B) Arteriovenous phase of fluorescein angiogram of same eye confirms the presence of abnormal pigment epithelium with patchy masking of the lesions.

anterior chamber or vitreous activity. Funda examination revealed a striking blotchy appearance of the retinal pigment epithelium and choroid, which looked like clouds beneath the retina (Fig 1A). The optic discs and retinal vessels were normal. A fluorescein angiogram confirmed the presence of lesions which were underneath the neuroretina These lesions masked fluorescence in an irregular pattern and there was no significan leakage in the late stages of the angiogram. The retinal component to the angiogram was normal (Fig 1B).

Although an opportunistic infection was suspected, this fundal picture was not recognised by us or by other specialists in HIV and so no treatment was given. During the next 2 weeks he became unwell with headaches and general lethargy. The differential diagnosis included cryptococcal meningitis, toxoplasma encephalitis, or cerebral lymphoma. Investigation showed a cryptococcal meningitis with an antigen level in both the CSF and serum of $1 \times 10^{6} \%$. He was treated with intravenous amphotericin for 10 days followed by a maintenance oral dose of fluconazole $(400 \mathrm{mg}$ daily). ${ }^{4}$ This resulted in regression not only of his systemic symptoms but also of his visual symptoms and dramatic resolution of the fundal changes over a 1 month period (Fig 2). A repeat lumbar puncture, 3 weeks later, showed mild improvement with reduction of the cryptococcal antigen level of $1 \times 10^{3} / 1$.

COMMENT

This case report describes a patient with visual symptoms and a rare fundal picture which, on fluorescein angiography, was consistent with pathology of either the retinal

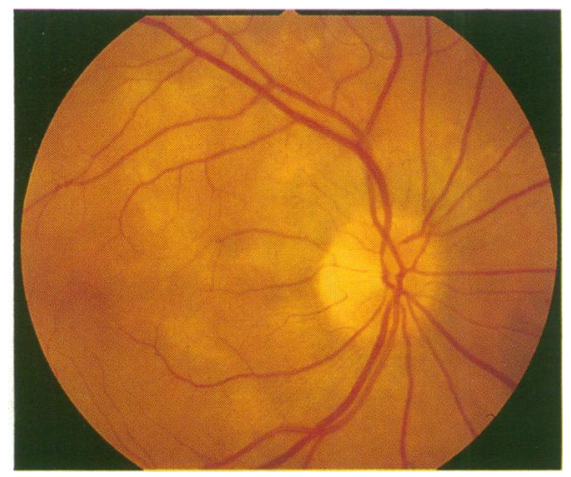

Figure 2 Right fundus 4 weeks later showing considerable resolution of the lesions. pigment epithelium or the choroid. A diagnosis of cryptococcal meningitis was eventually made and both the visual symptoms and the fundal abnormality resolved quickly on systemic treatment.

This is strong circumstantial evidence that the visual symptoms were due to the observed fundal abnormality and that Cryptococcus was the offending agent even in the absence of pathological proof.

The ophthalmologist plays a valuable role in the management of patients with AIDS since $70 \%$ of these patients have ocular disease. 56 Cytomegalovirus retinitis is the commonest ocular opportunistic infection and occurs in $30-40 \%$ of patients. The incidence of opportunistic infections which metastasise to the choroid is much lower and includes Cryptococcus neoformans, Mycobacterium avium, and Pneumocystis carinii. The prognosis for these patients is very poor by this stage but, nevertheless, the diagnosis may elude the physician until the choroidal involvement develops. It is, therefore, important for ophthalmologists to 'recognise' the pattern of choroidal involvement produced by opportunistic infections in AIDS as prompt treatment will prolong life.

SEEMA VERMA ELIZABETH M GRAHAM Department of Ophthalmology, St Thomas's Hospital

Correspondence to: Seema Verma, Department of Ophthalmology, St Thomas's Hospital, Lambeth Palace Road, London SE1 7EH

Accepted for publication 26 January 1995

1 Okum E, Butler WT. Ophthalmologic complications of cryptococcal meningitis. Arch tions of cryptococcal

2 Lesser RL, Simon RM, Leon H, Siegel N. Cryptococcal meningitis and internal ophthalmoplegia. Am f Ophthalmol 1979; 87: 682-7.

3 Morinelli EN, Dugel PU, Riffenburgh R, Ra NA. Infectious multifocal choroiditis in patients with acquired immune deficiency syndrome. Ophthalmology 1993; 100: 1014-21.

4 Nelson MR, Fisher $M$, Cartledge J, Rogers $T$, Gazzard BG. The role of azoles in the treatmen and prophylaxis of cryptococcal disease in HIV infection. AIDS 1994; 8: 651-4.

5 Mines JA, Kaplan HJ. Acquired immunodeficiency syndrome (AIDS): the disease and its ocular manifestations. Int Ophthalmol Clin its ocular manifes

6 Frangieh GT, Dugel PU, Rao NA. Ocula manifestations of acquired immune deficiency syndrome. Curr Opin Ophthalmol 1992; 3. 228-35.

7 Rosenblatt MA, Cunningham C, Teich S, with AIDS. $B r f$ Ophthalmol 1990; 74:610-4.

\section{Diagnosis and management of an occult} cyclodialysis cleft

EDITOR,-Non-intentional cyclodialysis may occur up to 6 months ${ }^{12}$ after anterior segment surgery or following trauma. ${ }^{34}$ The hypotony is due to aqueous outflow through the cleft to the uveoscleral pathway. 56 In these patients, there is normal aqueous production dynamics, 236 normal episcleral venous pressure, ${ }^{78}$ and an abnormal outflow facility. ${ }^{5}$ The cleft size is unrelated to the degree of the hypotony and maybe microscopic and hence occult. ${ }^{59}$

\section{CASE REPORT}

Preoperatively Mrs AB, a 53-year-old white woman, had visual acuities of $6 / 18$ in the left eye owing to cataract and perception of light in the right eye following retinal detachment. The left eye was otherwise normal and the IOP had varied from 11 to $15 \mathrm{~mm} \mathrm{Hg}$ over the preceding 5 years. A routine extracapsular cataract extraction with a limbal section and posterior chamber lens implantation was performed. The eye maintained an IOP of $11 \mathrm{~mm} \mathrm{Hg}$ until she banged her head 1 month later and the vision worsened. Examination revealed an IOP of $2 \mathrm{~mm} \mathrm{Hg}$ and a visual acuity of $6 / 9$. Gonioscopy did not reveal any cyclodialysis cleft. Four months postoperatively, the IOP remained at $2 \mathrm{~mm} \mathrm{Hg}$ but the refraction was dynamically unstable as a result of blinking and eye movements. An $8.0 \mathrm{~mm}$ diameter hard contact lens stabilised the corneal topography and the acuity at $6 / 9$. At 12 months, the IOP had remained at $2 \mathrm{~mm} \mathrm{Hg}$ but macular oedema reduced the acuity to $6 / 24$. There was no evidence of uveitis, no cleft was visible on gonioscopy, and ultrasound showed no evidence of choroidal or ciliary body detachment.

Laser flare studies revealed an anterior chamber flare count of 11 photon counts/ms, which was within normal limits for her age. Topical timolol increases the anterior chamber protein concentration in normal eyes by reducing aqueous production. Two hours after administration of timolol drops, the aqueous protein concentration had risen by $35 \%$ and by 4 hours it had risen to $63 \%$, compared with $75 \%$ in a normal eye Following intravenous injection of fluorescein, an area of increased scleral fluorescence was demonstrated adjacent to the original cataract section. These observations suggested an occult cyclodialysis cleft at the site of the previous surgical wound.

Gonioscopy with viscoelastic and surgical exploration of the wound failed to reveal a cleft. The wound was closed and the viscoelastic was removed. The IOP rose to $46 \mathrm{~mm}$ $\mathrm{Hg}$ at 12 hours and this required acetazolamide, mannitol, and levobunolol drops. By 10 days the IOP was $14 \mathrm{~mm} \mathrm{Hg}$ with the patient receiving levobunolol and dexamethasone, the choroidal folds had resolved, and the visual acuity was $6 / 9$.

For the next 10 months the IOP was $10 \mathrm{~mm} \mathrm{Hg}$ with no medication and the visual acuity was stable at 6/9. At 11 months, hypotony and macula oedema suddenly redeveloped. Argon laser trabeculoplasty to the wound region was unsuccessful on two occasions. Surgical gonioscopy and reexploration of the original wound failed to find a cleft. The scleral flaps were closed and 12 hours later the IOP had risen to $55 \mathrm{~mm} \mathrm{Hg}$. The pressure fell slowly to $14 \mathrm{~mm} \mathrm{Hg}$ over 14 days with medical treatment. One month later, the visual acuity was stable at $6 / 9$ and the IOP has remained at $14 \mathrm{~mm} \mathrm{Hg}$ on no treatment for 6 months.

\section{COMMENT}

The diagnosis of cyclodialysis requires an assessment of aqueous production and the facility of outflow but the latter is not possible because the eye is hypotonous. Therefore the cleft requires visualising with gonioscopy, sometimes with perioperative chamber deepening. With an occult cleft the diagnosis depends on proving both normal aqueous production and an abnormal outflow pathway.

Aqueous production must fall to less than $10 \%$ of normal to produce hypotony ${ }^{6}$ so that any test which shows approximately normal aqueous dynamics excludes ciliary body dysfunction as the cause of hypotony. Laser flare measurements can quantify the amount of protein in the anterior chamber aqueous. 
The presence of a normal flare count and the increased protein concentration by $63 \%$ after timolol was highly suggestive that the ciliary body was producing normal amounts of aqueous in this case. ${ }^{10}$ Similar observations can be made with fluorophotometry. ${ }^{3}$

The anatomical site of the cleft was suggested by the scleral staining after an intravenous injection of fluorescein. An alternative method would be to inject the fluorescein directly into the anterior chamber ${ }^{7}$ but this was considered too hazardous in an only eye. However, the technique may be useful during surgery as drainage of fluorescein stained fluid from a sclerotomy site would indicate a patent cleft and that the sclerotomy is close to the cleft. ${ }^{1}$

This case illustrates that occult clefts can be confirmed using laser flare measurements, provocative testing with timolol, and intravenous fluorescein. Hypotony induces a dynamically unstable refraction which can be stabilised with a hard contact lens. Closure of the cleft can then be attempted with argon laser, diathermy, cryotherapy, or surgery. If the distance across the cleft is small, the tissues may appose solely from the inflammatory swelling but if the distance is large, sutures or plombage may be required. 1346

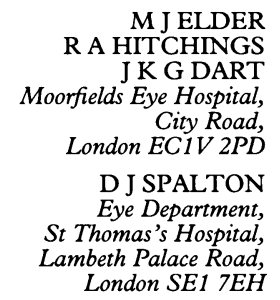

Correspondence to: $\mathrm{Mr} \mathrm{M} \mathrm{J}$ Elder.

Accepted for publication 2 February 1995
1 Maumenee AE, Stark WJ. Management of persistent hypotony after planned or inadvertent tent hypotony after planned or inadvertent
cyclodialysis. Am 7 Ophthalmol $1971 ; 71: 320-7$.

2 Barasch K, Galin MA, Baras I. Postcyclodialysis hypotony. Am f Ophthalmol 1969; 68: 644-5.

3 Pederson JE. Hypotony. In: Duane TD, ed. Clinical ophthalmology. Pennsylvania: Harper and Row, 1988; Vol 3, Ch 58: 4.

4 Demeler U. Surgical management of ocular hypotony. Eye 1988; 2: 77-9.

5 Bill A. The routes for bulk drainage of aqueous humour in rabbits with and without cyclohumour in rabbits with and without cyclo-

6 Pederson JE. Ocular hypotony. Trans Ophthalmol Soc UK 1986; 105: 220-6.

7 Kronfield PC. The fluid exchange in the successfully cyclodialyzed eye. Trans Am Ophthalmol Soc 1954; 52: 249-63.

8 Stepanik J. Die tonographie und der episklerale venendruck. Ophthalmologica 1957; 133: $397-406$.

9 Chandler PA, Maumenee AE. A major cause of hypotony. Am ₹ Ophthalmol 1961; 52: 609-18.

10 Mori M, Araie M. A simple method of determining the time course of timolol's effect on aqueous flow in humans. Arch Ophthalmol 1991; 109: 1099-103. 